\title{
Why Should We Closely Monitor Fecundity in Marine Fish Populations?
}

\author{
Yvan Lambert \\ Ministère des Pêches et des Océans, Institut Maurice-Lamontagne, \\ C.P. 1000, Mont-Joli, Québec, G5H 3Z4, Canada. \\ E-mail: yvan.lambert@dfo-mpo.gc.ca
}

Lambert, Y. 2008. Why Should We Closely Monitor Fecundity in Marine Fish Populations? J. Northw. Alt. Fish. Sci., 41: 93-106. doi:10.2960/J.v41.m628

\begin{abstract}
Reproductive success, best defined as lifetime total offspring to reach maturity, is the product of the number of eggs produced (i.e., fecundity) per season, adult reproductive life span and offspring survival to maturity. Life history traits at the population level can be seen as a representation of the fate of individuals through their life cycle. For practical purposes, reproductive success is often separated in two components: reproductive potential and offspring survival to maturity. In studies of exploited marine fish populations, spawning stock biomass (SSB) is commonly used as a proxy of reproductive potential instead of direct measures of the egg production of the stock. This technique assumes, however, that egg production per unit of biomass is time-invariant. This assumption is unsupported by a review of the literature. Seasonal fecundity varies in relation to parental quality (e.g., size, condition), resource availability (e.g., food abundance and quality), environmental (e.g., temperature) and evolutionary factors (e.g. stock biomass, fishing pressure). Recent studies and use of generalized linear models to hindcast fecundity variations demonstrate that stock reproductive potential estimated by the total egg production can lead to different perceptions of the state and productivity of the stock. The recent development of cost-effective methods to count egg numbers of fish now makes it practical to routinely determine potential fecundity. Adding measures of fecundity to other demographic parameters that are already commonly measured for exploited marine fish stocks allows a more precise measurement of the reproductive potential. One possible outcome of measuring reproductive potential as demonstrated using northern Gulf of St. Lawrence cod as a case study is the calculation of the intrinsic rate of population increase $(r)$, an essential parameter in population dynamics and evolutionary ecology, which can be used in determining sustainable harvesting, resilience, and potential rates of recovery of populations.
\end{abstract}

Key words: fecundity, intrinsic rate of population increase, life history, stock-recruitment, reproductive potential, reproductive success.

\section{Introduction}

Reproductive success can best be defined as the passing of genes onto the next generation in a way that they too can pass those genes on (Clutton-Brock, 1988). It is a key element in the theories of natural selection and evolution. Reproductive success can be represented as lifetime total offspring to reach maturity; it is estimated as the product of fecundity per season (number of offspring per mating event and number of mating events per season), adult reproductive life span and offspring survival (Clutton-Brock, 1988). However, determining individual life span and the fate of offspring produced by individuals is not easy and may be impossible for many aquatic species (Vincent and Giles, 2003). However, at the population level, variations in life history traits might be used as a representation of the life cycle of individuals (Caswell, 2001).

Reproductive success is often broken into two components: reproductive potential and offspring survival to maturity. In fisheries, total stock egg production and recruitment to the fishery can be seen as measures of these two components. For most exploited marine species, fecundity is related to recruitment variation (Rickman et al., 2000), and stock-recruitment models representing relationship between parental population and number of offspring produced are widely used to assess stock viability (Marshall et al., 2006). Different stock-recruitment models have been developed (Ricker, 1954; Beverton 
and Holt, 1957; Shepherd, 1982), but a high degree of unexplained variability of the data around each model is a common problem. It is of more than historic interest, however, to note that these models were originally based on relations between fecundity of the stock and recruitment (Rothschild and Fogarty, 1989; Koslow, 1992) but that spawning stock biomass (SSB) has generally been regarded as an index of fecundity when fitting such models. It cannot simply be said that SSB is a common metric in stock-recruitment models, particularly in marine fish populations, but also that direct measurement of fish fecundity is rare. For example, between 1878 and the mid-1990s, individual fecundity for all northwest Atlantic cod stocks was measured for $\sim 600$ fish (Trippel, 1999). Tomkiewicz et al. (2003) observed that fecundity data was rarely available to determine the total egg production of 42 Northwest Atlantic groundfish stocks, for any year, let alone a time series.

The use of spawning stock biomass (SSB) as a proxy for stock total egg production (TEP) implies that the fecundity of the mature fish is independent of their age, body size, or condition, and that annual egg production per unit weight of adult stock is not variable over time. These assumptions are challenged in many studies (Marshall et al., 2003; Tomkiewicz et al., 2003; Yoneda and Wright, 2004; Murua et al., 2006). There is increasing evidence indicating that direct proportionality between SSB and stock egg production may not always exist (Marshall et al., 1998; Marshall et al., 1999; Scott et al., 1999; Trippel, 1999; Marteinsdottir and Begg, 2002).

This paper reviews some general factors that affect fecundity for marine fishes in general and includes specific examples for Atlantic cod (Gadus morhua) and herring (Clupea harengus). Next, the case for routinely measuring fecundity in marine fish populations is made, particularly in light of new methodological developments. The capacity to develop fecundity models to hindcast variations in potential fecundity and total egg production of stocks is also examined. Finally, the use of fecundity data to determine reproductive success and develop alternative measurements of population dynamics in exploited marine fish is explored.

This paper largely relies on published data. However, for some of the objectives, published data from different studies were also re-analysed and/or presented differently. Finally, specific data collated for the northern Gulf of St. Lawrence cod population are used as an example for the development of fecundity models and to demonstrate how the measurement of reproductive characteristics of fish population can be used to develop alternative measurement of population growth.

\section{Fecundity Definitions and Methods of Determination}

The number of eggs produced per female has been variously defined in fisheries literature and different fecundity terms have been used in relation to the reproductive strategy of the fish and oocyte recruitment or stages. Definitions of reproductive strategies, spawning pattern, ovarian organization and fecundity terms used in the present review are found in (Murua et al., 2003; Murua and Saborido-Rey, 2003). In most studies, fecundity usually refers to potential annual fecundity, which represents the total number of advanced yolked oocytes matured per female and year, uncorrected for atretic losses $(\mathrm{Mu}-$ rua et al., 2003). As in many studies, the term potential fecundity used throughout the present paper represents potential annual fecundity.

The estimation of fecundity usually refers to the determination of the number of vitellogenic oocytes (i.e., potential fecundity). Different methods exist but their use will depend on the species under investigation, resources and laboratory facilities available (Murua et al., 2003). Traditionally, potential fecundity is determined by a gravimetric or volumetric method (Bagenal, 1978; Kjesbu and Holm, 1994). Although these methods are simple, inexpensive and give reliable results, the work is time-consuming and tedious (Thorsen and Kjesbu, 2001). However, new methods are developed to reduce the time and labor involved in measuring fecundity. For example, Thorsen and Kjesbu (2001) developed a method to measure oocyte density (number of eggs/g) using an image analysis system. An image analyser was used to automatically determine mean oocyte diameter of a gonad sample and the oocyte density was determined with a calibration curve. In general, it took 5 minutes to prepare the sample, measure oocyte diameter and process the data. Similarily, procedures based on image analysis have also been developed to measure efficiently and at low cost potential fecundity (Friedland $e t$ al., 2005; Klibansky and Juanes, 2008). Although some validation process is necessary before using these methods, they represent a major advancement in the efficient measurement of potential fecundity.

\section{Biological Constraints of Fecundity}

Potential fecundity is strongly influenced by female size, trade-off between egg size and egg number, reproductive strategy and spawning pattern of the species. While size of oocytes will have a direct influence on maximum number of hydrated oocytes that can be produced in one time, reproductive strategy and spawning pattern will determine the possible number of eggs that 
can be produced in the spawning season. Species with indeterminate fecundity where potential annual fecundity is not fixed before the onset of spawning will have the capacity to produce more eggs than species with determinate fecundity where new vitellogenic oocytes are not produced during the spawning season. In the same way, batch spawners which released hydrated eggs in batches over a protracted spawning period will have the capacity to produce more eggs than total spawners where all oocytes are hydrated and shed in a single episode.

Because female fish retain their oocytes internally during their development, maximum reproductive output will be subjected to morphological constraints. The volume of the body cavity will limit the reproductive allocation at each spawning event. This limitation will result in correlations between reproductive investment and fish size. As the volume of body cavity is related to size, the potential fecundity in many fish species is strongly related to body size (Wootton, 1992, 1999). Female size explained $25-98 \%$ of the variability in the potential fecundity of different freshwater and marine species (Kamler, 2005). In a review of the potential fecundity of Atlantic cod (Gadus morhua) for different stocks, years, and size range of fish, 38-90\% of the variability in potential fecundity was explained by female size (Lambert et al., MS 2005). This large influence of size is clearly demonstrated by the general use of relationships between fecundity and female size (usually expressed as length or weight) to describe variations in the fecundity of marine fish species.

The constraint associated with the volume of the body cavity can also result in a trade-off between egg size and egg number; larger egg volume decreasing the maximum number of eggs that can be produced. The inverse relation between egg size and egg number in spring and autumn spawning herring, a total spawner with determinate fecundity is a known example of this possible trade-off (Hempel and Blaxter, 1967; Winters et al., 1993).

Female attributes other than size have also been shown to influence potential fecundity. Variations in the nutritional status estimated from different indices of condition like the condition factor or liver index significantly influence potential fecundity of Atlantic cod, plaice (Pleuronectes platessa), and sole (Solea solea) (different studies reviewed in Lambert et al., 2003). Variability in batch fecundity in some pelagic species (Milton et al., 1995; Yamada et al., 1998) and in seahorses (Vincent and Giles, 2003) has also been related to the nutritional status of the fish (i.e., condition factor). Independent of size, age and reproductive experience (defined as first $v s$ repeat spawners) also influence potential fecundity. For example, first time spawners of Atlantic cod had lower realized annual fecundity (number of eggs released per female in a year) than repeat spawners of similar size (Trippel, 1998).

\section{Ecological Constraints of Fecundity}

Besides the determinant influence of female size, potential fecundity is also modulated by environmental conditions. Numerous studies showed relations between potential fecundity and many environmental factors such as food abundance/ availability/ consumption, temperature, fish density, and biomass index (Trippel, 1998; Lambert et al., 2003; Kamler, 2005). Laboratory studies demonstrated the positive relation between potential fecundity and food ration in haddock (Melanogrammus aeglefinus), plaice, herring and winter flounder (Pseudopleuronectes americanus) (Tyler and Dunn, 1976; Hislop et al., 1978; Horwood et al., 1989; Ma et al., 1998). In natural environment, prey abundance/density has been related to potential fecundity in cod (Kjesbu et al., 1998; Marshall et al., 1999; Kraus et al., 2002) and to batch fecundity in the anchovy (Encrasicolina heteroloba) (Milton et al., 1995). Correlations between biomass index and potential fecundity were observed for herring and cod with higher potential fecundity observed in periods of lower biomass levels (Winters et al., 1993; Yoneda and Wright, 2004). Finally, higher temperature is associated with higher potential fecundity in cod (Kjesbu et al., 1998; Kraus et al., 2000) and herring (Tanasichuk and Ware, 1987) and higher batch fecundity in the anchovies (E. heterobola and Engraulis japonicus) (Milton et al., 1995; Funamoto and Aoki, 2002).

Variability in environmental conditions will directly or indirectly through their influence on growth and nutritional status result in a wide range of variation in potential fecundity. This variability is clearly demonstrated by the different potential fecundity-size relationships (length is commonly used as the measure of size) observed for many species in the literature. Annual variations in these relationships can be seen as the response of individual females to varying combination of biological and environmental influential factors. For mainly most marine fish species, significant differences in relationships between potential fecundity and length have been detected between populations, geographic areas, and years (Almatar and Bailey, 1989; Winters et al., 1993; Kraus et al., 2000; Marteinsdottir and Begg, 2002; Lambert et al., 2003). For example, the examination of the relationships for 13 Atlantic cod stocks covering periods 
of 2-10 years for each stock indicated an extremely large variation in the fecundity of this species (Lambert et al., MS 2005). The potential fecundity varied from 150 000-25 million eggs (Fig. 1). A 10-fold difference in potential fecundity was observed for a $60 \mathrm{~cm}$ female
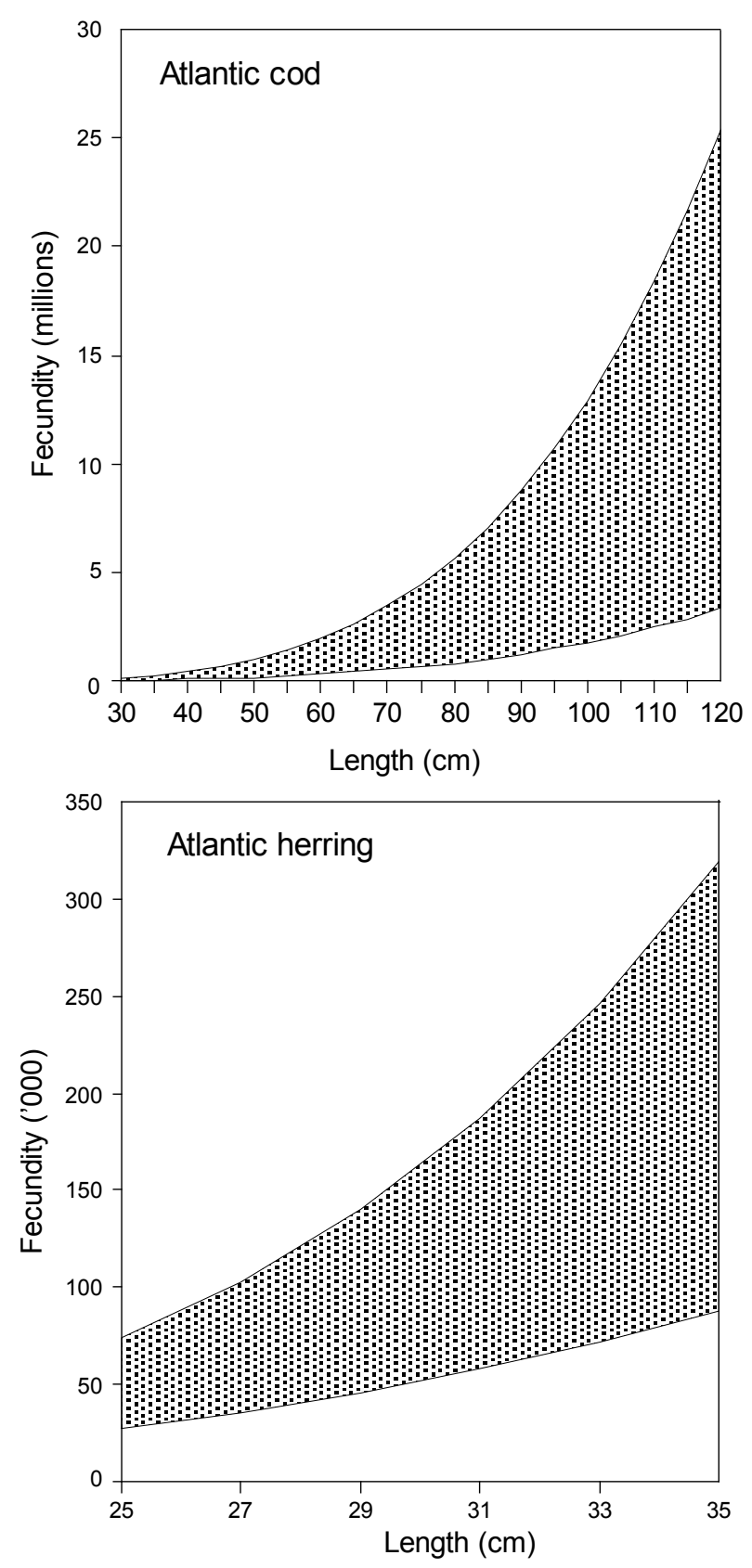

Fig. 1. Range of variation in the potential fecundity-length relationships of Atlantic cod (Gadus morhua) and Atlantic herring (Clupea harengus). Minimum and maximum values of fecundity for each species were obtained from studies on potential fecundity-length relationships observed for different populations, geographic areas and years. (range: 209 000-2.2 million eggs). Moreover, the examination of the relationships between potential fecundity and length indicated important variations in the relative fecundity with size; the slopes of the relationships varying between 1.15-5.46 (Lambert et al., MS 2005). This variability indicates that relative potential fecundity (number of yolked oocytes per g of female weight) will be variable with size. Although showing a lower extent of variation, potential fecundity within cod populations is nevertheless significantly different from year-to-year. Significant differences in the order of $33 \%, 44 \%$ and between 14-106\% depending on size, were observed between years in potential fecundity for Baltic, Northeast Arctic and Icelandic cod populations, respectively (Kjesbu et al., 1998; Kraus et al., 2000; Marteinsdottir and Begg, 2002).

Although of a lower amplitude than for Atlantic cod, potential fecundity in Atlantic herring is also very variable (Fig. 1). Studies of Atlantic herring populations from both sides of the North Atlantic indicate a variation in potential fecundity between 14 000-301 000 eggs for fish in a size range of 24-38 cm (Messieh, 1976; Kelly and Stevenson, 1985; Almatar and Bailey, 1989; Winters et al., 1993; Oskarsson and Taggart, 2006). A 2- to 3-fold difference in the potential fecundity for a fixed size is observed. A large proportion of this variability is associated with the spawning time of the fish. For example, for a fixed size of $33 \mathrm{~cm}$, the potential fecundity varies between $72000-145000$ in spring spawners compared to 99 000-175000 in autumn spawners. This difference in potential fecundity is largely associated with differences in egg size. In the North Sea, egg weight for spring spawners varied between $25.3-30.8 \mathrm{mg} / 100$ eggs compared to a variation between $14.3-18.7 \mathrm{mg} / 100$ eggs for autumn spawners (Almatar and Bailey, 1989). As observed for Atlantic cod, large variations in the slopes of the fecundity-length relationships were observed with the lowest slope having a value of 3.31 and the steepest one a value of 6.03. These studies showed significant differences in the slopes and intercepts of the relationships between populations, between spawning groups (i.e., spring and autumn spawners), and between years within populations.

The influence of a combination of environmental factors on potential fecundity may be a more complex response than a simple cumulative effect of these different influential factors. Specific combinations of environmental factors may impose some constraints on the possible patterns of energy allocation between maintenance, growth, and reproduction of the fish. The comparison of potential fecundity of Atlantic cod populations of Georges Bank (GB) and Southern Gulf of St. Lawrence 
(SGSL) which are found in different environmental conditions is supporting this idea. In a study on the productivity of North Atlantic cod stocks, SGSL cod stock has been classified as one of the less productive stocks and GB cod stock in a group of more productive stocks (Dutil and Brander, 2003). Potential fecundity measurements made from 1998-2000 indicated, with combined data of different years in each stock, that the size-specific potential fecundity of SGSL cod was $27 \%$ higher than in GB cod (McIntyre and Hutchings, 2003). Higher gonadosomatic index (GSI) were also observed for SGSL cod in the same study. These differences between the stocks were interpreted as an indication of higher reproductive investment in SGSL in response to slower growth, longer time to reach maturity, and higher pre-reproductive mortality (McIntyre and Hutchings, 2003).

Data from McIntyre and Hutchings (2003) study and assessment documents for GB and SGSL cod stocks (Chouinard et al., MS 2005; O'Brien et al., MS 2006) allow the examination of the allocation of energy between growth and reproduction in these stocks. Length and weight data at age from SGSL and GB cod assessments documents and corresponding GSI (McIntyre and Hutchings, 2003) were used to estimate the allocation of total weight increment during a year between somatic growth and reproductive investment (Fig. 2). In the period of 1998-2000, GB cod reached a length of $\sim 75 \mathrm{~cm}$ and a weight of $\sim 4.6 \mathrm{~kg}$ at age 5 (O'Brien et al., MS 2006) while similar length and weight were observed at age 14 in SGSL cod (Chouinard et al., MS 2005). Surplus mass (increase in somatic mass plus increase in gonad mass estimated from GSI) accumulated over two successive years was calculated for cod of similar size (i.e., $65-75 \mathrm{~cm}$ ) using corresponding ages for each stock. GB cod which is having higher growth rate than SGSL had $37-44 \%$ of its surplus mass invested in reproduction compared to $54-58 \%$ for SGSL cod (Fig. 2). The end result is that size-specific potential annual fecundity is higher in SGSL cod even if the stock is among the less productive in the North Atlantic.

\section{Modeling Fecundity}

In the review so far, it is apparent that fecundity can vary widely between individuals of the same population (e.g., by female size), and between years, populations, and species. Furthermore, these variations are likely to be adaptive and such variation has obvious importance for stock assessment and management of fisheries. So, then, it may seem remarkable that as a life history trait, fecundity is rarely monitored. In contrast, data on age, size, weight, sex and maturity are extensively collected for many marine fish stocks which allows the use of time

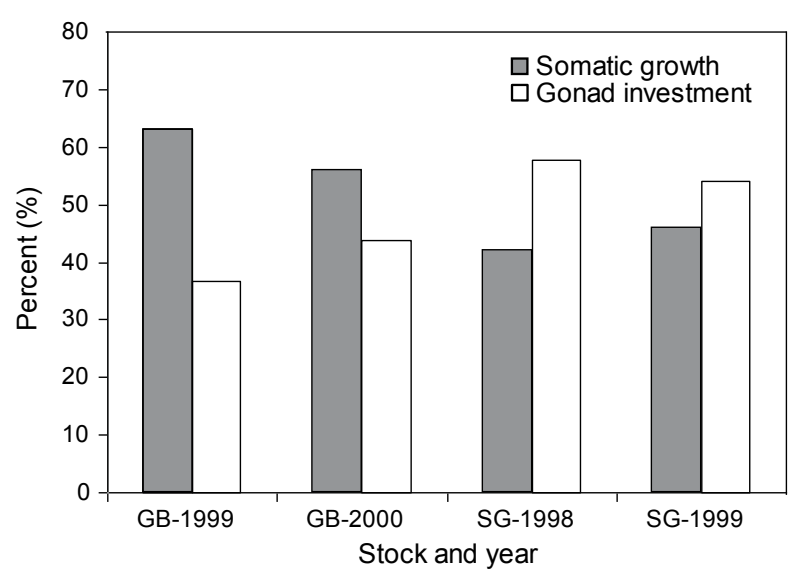

Fig. 2. Somatic growth and gonad investment as proportion of the surplus mass accumulated during the year for Atlantic cod from southern Georges Bank (GB, 1999 and 2000) and Gulf of St. Lawrence (SG, 1998 and 1999). Mass allocations were calculated for ages of fish corresponding to lengths of $65-75 \mathrm{~cm}$. Data were obtained from the studies of McIntyre and Hutchings (2003), Chouinard et al. (MS 2005), and O'Brien et al. (MS 2006).

series of annual data for assessing age structure, abundance at age, spawning stock biomass (Tomkiewicz et al., 2003). The absence of time series on fecundity may be associated with the large use of SSB as a proxy of reproductive potential and stock-recruitment relationships in age-structured population models. Moreover, for analysis requiring information on the egg production, many studies rely on potential fecundity data from the same stock but measured at a different time period or potential fecundity data coming from other stocks assuming unimportant effect of variability in potential fecundity.

Time and cost limitations may be responsible for the absence of monitoring of the fecundity. However, as described earlier, new methods and procedures developed in recent years provide tools to monitor on a regular basis the potential fecundity. Recent studies examining alternative and more accurate measures of reproductive potential stimulated the interest in measuring more closely the variability in potential fecundity an its influence on stock reproductive potential.

The variability in potential fecundity between years observed for different species and stocks has been analysed in relation to influential factors known to modulate potential fecundity (Kraus et al., 2000; Lambert and Dutil, 2000; Marteinsdottir and Begg, 2002; Blanchard et al., 2003; Yoneda and Wright, 2004; Thorsen et al., 2006). Potential fecundity of Northeast Arctic (NEA) cod determined during a period of large interannual variation 
in the condition factor (Kjesbu et al., 1998; Yaragina and Marshall, 2000) demonstrated the significant effect of condition on potential fecundity (Thorsen et al., 2006). Based on this observation, a multiple regression model relating potential fecundity to total length and Fulton's condition factor explained $93 \%$ of the total variability of NEA cod during the period from 1986-2004 (Thorsen et al., 2006). In haddock (Melanogrammus aeglefinus), similar models based on length and relative condition factor and length and hepatosomatic index were used to predict variation in the potential fecundity (Blanchard et al., 2003). However, condition factor did not always explain a significant proportion of the variability in potential fecundity. For example, prey availability index was a better predictor of fecundity in Baltic cod than condition factor (Kraus et al., 2002). A simple model obtained with an exponential function relating relative potential fecundity to prey availability index explained $72 \%$ of the variability in the potential fecundity between years.

Generalized linear models using co-variate or multiple regression factors to incorporate significant influential factors explaining inter-annual variations in potential fecundity can advantageously be used to hindcast and predict variations in potential fecundity. As already mentioned, potential fecundity is not monitored routinely in most stocks. However, other variables like the condition factor that explains a significant proportion of the variability in potential fecundity in many stocks is estimated from length and weight data that are often available on a regular basis. Thus, generalized linear models based on length and condition factor can be used to explain a large proportion of the yearly variability in potential fecundity and hindcast time series of variations in potential fecundity. These models could clearly be used to reconstruct potential fecundity time series.

\section{Applications of Fecundity Data to Stock Assessment}

The combination of time series of potential fecundity data obtained from monitoring and/or the development of generalized linear potential fecundity models to demographic parameters largely available for exploited marine fish stocks allows the monitoring of total egg production of stocks (TEP). TEP which represents the total number of advanced yolked oocytes (i.e., potential annual fecundity) produced by a population in a breeding season will be dependent on the number of fish at age, size at age, sex ratio, proportion of females mature at age and potential fecundity (Trippel, 1999).

Reconstruction of potential fecundity time series were used to examine the variation in the reproductive potential of different species and stocks. For Eastern Baltic cod, TEP proved to be superior to SSB as a measure of stock-recruitment relationship (Kraus et al., 2002). The estimation of TEP for NEA cod gave a different interpretation of the recruitment response to reductions in stock size than the use of SSB (Marshall et al., 2006). On the other hand, TEP which was considered as the best estimate of the reproductive potential of haddock on the eastern Scotian Shelf did not notably improve the stock-recruitment relationship although it generated a new viewpoint of stock dynamics (Blanchard et al., 2003). For different cod stocks around Newfoundland, estimates of reproductive potential produced by including this improved biological information changed the perception of the size of the spawning stock and levels of stock productivity as measured by reproductive rate and spawning stock produced per recruit (Morgan and Brattey, 2005).

The differences in the coefficients of determination $\left(r^{2}=0.26-0.8\right)$ in the relationships between TEP and SSB for different cod and haddock stocks indicate variable levels of dependence between the two (Marshall et al., 2003). However, even in the presence of high correlation between TEP and SSB, the use of TEP can be justified by the fact that it is incorporating precise reproductive characteristics of the stock (Marshall et al., 2003). Moreover, the determination of TEP and the estimation of the number of recruits allow the calculation of survival rates of individual cohorts. Thus, adding the monitoring of potential fecundity to the biological information on age, length, maturity, weight, and sex that are recorded annually in most exploited marine fish stocks can be used to build time series on the variation in TEP and recruitment.

\section{Case Study: Northern Gulf of St. Lawrence (NGSL) Cod}

An ongoing study on the variations in the reproductive potential of cod in the northern Gulf of St. Lawrence is used to demonstrate the application of an efficient method to routinely measure potential fecundity, to evaluate a fecundity model tracking annual changes in potential fecundity, and to determine TEP for this stock. The use of the different demographic parameters determining reproductive potential is also examined in relation to the reproductive success of the stock and as an alternative method for the measurement of population dynamics in exploited marine fish.

Data on the potential fecundity of NGSL cod obtained in 1995 and 1998 (Lambert and Dutil, 2000; Lambert et $a l ., 2000)$ are combined to new potential fecundity data 
obtained from samples collected in 2001 and 2002 in the northern Gulf of St. Lawrence and Southern Newfoundland (NAFO divisions 3Pn4RS and 3Ps, respectively). These data were used to apply the auto-diametric method (Thorsen and Kjesbu, 2001) for the determination of the potential fecundity of cod in the NGSL and to develop a multiple regression model describing the interannual variations in potential fecundity of the stock.

Biological characteristics of cod in the northern Gulf of St. Lawrence necessary to estimate TEP were collated from information on age, length, maturity, weight and sex data that are recorded annually by the Canadian Department of Fisheries and Oceans during annual groundfish survey (DFO, MS 2007), Groundfish Sentinel Fisheries Program (http://www.osl.gc.ca/pse/en/), and supplementary research surveys conducted during the pre-spawning period in 1995 and 1998. Population numbers-at-age, lengths-at-age, sex ratio-at-age, and the proportion of females that are mature-at-age were derived from these data. Total egg production (TEP) of the stock was estimated as:

$$
T E P=\sum_{x=3}^{13} N_{x} r_{x} p_{x} f_{x}
$$

where $N_{x}$ represents the number of fish at age $x$ estimated from the SPA (Fréchet et al., MS 2005), $r_{x}$ the sex ratio at age, $p_{x}$ the proportion of mature females at age $x$, and $f_{x}$ the potential fecundity at age $x$.

\section{Auto-diametric Fecundity Method for NGSL Cod}

The ovary samples of Atlantic cod collected in 2001 and 2002 in different areas of the northern Gulf of St. Lawrence and Southern Newfoundland (Table 1) were used to determine the number of yolked oocytes/g ovary and mean yolked oocyte diameter of each fish. The number of yolked oocytes/g ovary (NOG) was determined using a traditional volumetric method (Lambert and Dutil, 2000) and mean yolked oocyte diameter (OD) was evaluated using an image analysis system (Thorsen and Kjesbu, 2001). Calibration curves relating OD to NOG were estimated for the different areas and years (Fig. 3). Analysis of covariance on log transformed data indicate that calibration curves for the different years and areas are identical. Morever, the following relationship calculated for the grouped data:

$$
N O G=1862.7 O D^{-2.5933}
$$

$\left(r^{2}=0.93\right)$ is essentially the same as the one developed for Northeast Arctic cod by Thorsen and Kjesbu (2001). A difference of less than $6.5 \%$ is observed between NOG estimated with the two calibration curves indicating that these relationships could be valid for most Atlantic cod stocks. This relationship may as well be applicable to other species as the specific density of yolked oocytes determined by the yolked oocyte weight per unit of volume may result in similar relation between OD and NOG for different species. Specific density of vitellogenic oocytes which is largely associated with water, lipid and protein contents may not be variable enough due to differences in the relative composition of the oocytes and specific density of water, proteins and lipids to result in significant differences in NOG. In a review of 25 marine and freshwater fish species, Kamler (2005) observed a small range of caloric value of egg dry matter (20-30 J $\mathrm{mg}^{-1}$ ) for freshly spawned eggs indicating similar protein and lipid composition of vitellogenic oocytes before hydration.

This apparent stability in the calibration curve relating NOG to OD might indicate that the "auto-diametric fecundity method" presented by Thorsen and Kjesbu (2001) can possibly represent an efficient method for the measurement of potential fecundity for many species and stocks. Then, this approach would allow accurate and fast measurement of potential fecundity and provide a tool to easily monitor yearly variations in potential fecundity.

TABLE 1. Samples of Atlantic cod from northern Gulf of St. Lawrence and southern Newfoundland used for potential fecundity analysis. Year, sampling months, geographic area with NAFO divisions in parenthesis and number of fish are presented.

\begin{tabular}{cclr}
\hline \hline Year & Date & \multicolumn{1}{c}{ Sampling area } & $n$ \\
\hline 2001 & Apr-May & northern Gulf of St. Lawrence (4R) & 171 \\
2002 & Apr-May & northern Gulf of St. Lawrence (4R) & 72 \\
2001 & Apr-May & northern Gulf of St. Lawrence (3Pn) & 49 \\
2001 & Apr-May & southern Newfoundland (3Ps) & 84 \\
\hline
\end{tabular}




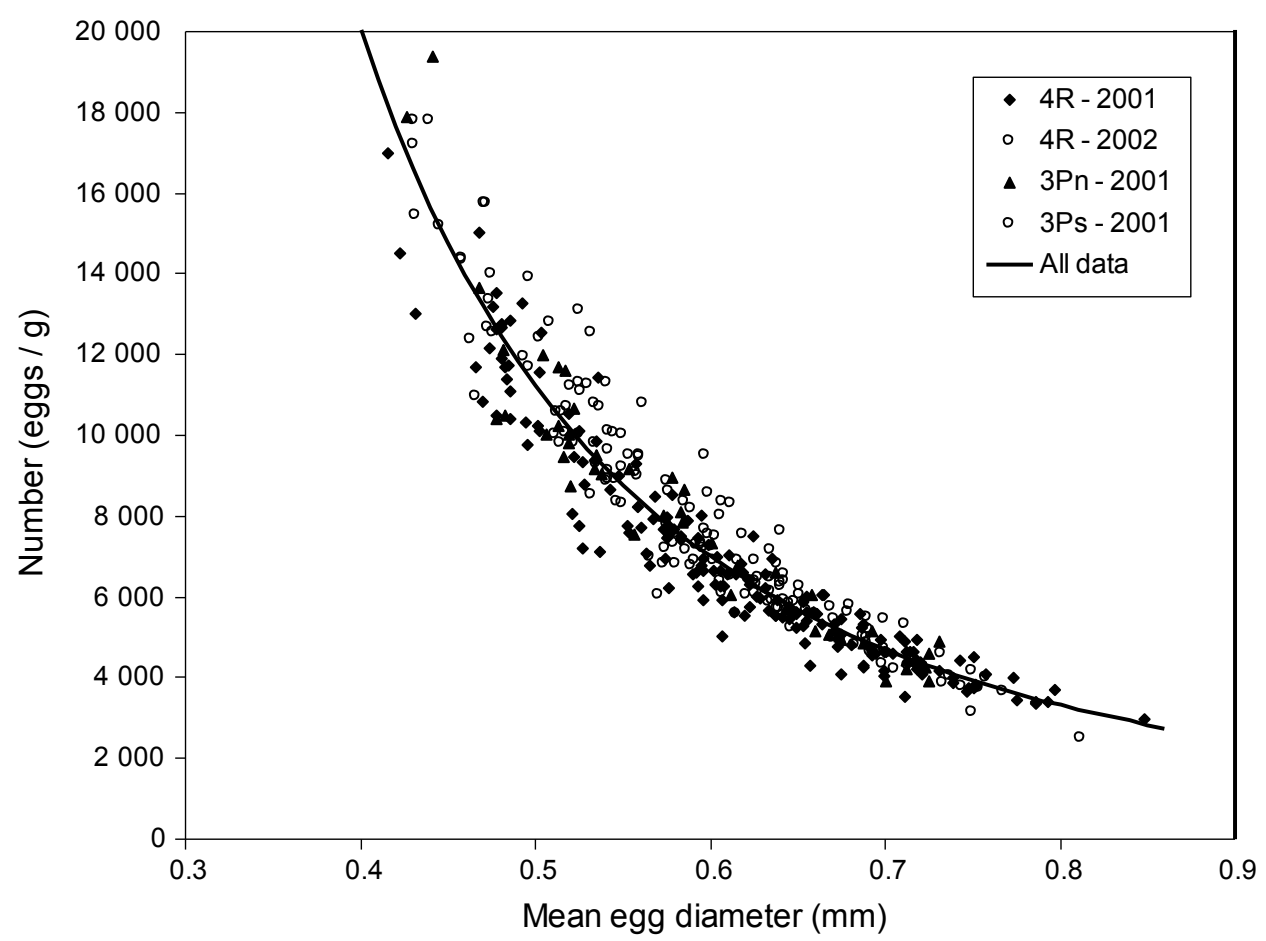

Fig. 3. Relationship between mean egg diameter and number of eggs/g for Atlantic cod sampled in different areas and years. Data for cod from the northern Gulf of St. Lawrence (4R and 3Pn) and southern Newfoundland (3Ps) are presented along with the relationship for combined data as no significant differences were observed between areas and years.

\section{Multiple Regression Model Describing Interannual Variation in Potential Fecundity}

Interannual variations in potential fecundity of NGSL cod are examined by comparing potential fecundity-length relationships observed in 1995, 1998, 2001, 2002. Significant differences in the potential fecunditylength relationships are observed between the years (Table 2, Fig. 4). Comparisons of slopes obtained with linear regressions on log transformed data and adjusted means with ANCOVA indicate that the potential fecundity was lowest in 1995 and highest in 1998. Mean condition factor for maturing fish sampled at the same periods and years showed similar variation. Significant differences (1-way ANOVA and Tukey's test) were observed between the years with the lowest condition factor value in 1995 and the highest value in 1998 (Fig. 4). Laboratory experiments with NGSL cod demonstrated similar significant effects of condition factor on realized fecundity (Kjesbu et al., 1991; Lambert and Dutil, 2000). A multiple regression model using length and condition factor as dependent variables explained $72 \%$ of the variability in realized fecundity (i.e., number of eggs released by a female during the breeding season).

The dependence of potential fecundity on length and condition factor was also evaluated in natural envi- ronment. A multiple regression model indicated that both fork length and condition factor had significant effects on potential fecundity (Table 3). The regression model explained $79 \%$ of the total variability in potential fecundity. The model describing the potential fecundity ( $f e c$, millions of eggs) in relation to fork length $(L, \mathrm{~cm})$ and condition factor $(K s)$ was:

$$
f e c=\exp (-14.525+3.630 \ln L+1.515 \ln K s)
$$

Given the high proportion of the total variability in potential fecundity explained by this regression model, a time series of the changes in potential fecundity for NGSL cod based on length and interannual variation in the condition factor could be estimated. Length and weight data available in different surveys conducted since 1984 might be used to analyse the annual variation in the condition factor of maturing female cod and construct a time series describing the changes in potential fecundity between years.

\section{Determination of Rate of Population Increase from Information on Reproductive Potential}

The yearly monitoring of potential fecundity and other demographic parameters commonly obtained from surveys provides the empirical values necessary to determine age-specific rates of survival and fecundity and 
TABLE 2. Regression parameters of the relationships between potential fecundity and fork length $\left(Y=a X^{b}\right)$ for cod sampled in the northern Gulf of St. Lawrence. For each relationship, year of sampling, sampling months, size range of fish, the slope $(b)$, the intercept $(a)$, the coefficient of determination $\left(r^{2}\right)$ and the number of observations $(n)$ are presented.

\begin{tabular}{rlcllcr}
\hline \hline Year & Sampling & Size range $(\mathrm{cm})$ & \multicolumn{1}{c}{$b$} & \multicolumn{1}{c}{$a$} & \multicolumn{1}{c}{$r^{2}$} & \multicolumn{1}{c}{$n$} \\
\hline 1995 & Apr-May & $37-65$ & 3.964 & 0.065 & 0.70 & 53 \\
1998 & Apr-May & $35-60$ & 3.86 & 0.151 & 0.72 & 120 \\
2001 & Apr-May & $37-90$ & 3.265 & 1.4587 & 0.79 & 220 \\
2002 & Apr-May & $36-65$ & 3.527 & 0.499 & 0.73 & 72 \\
\hline
\end{tabular}
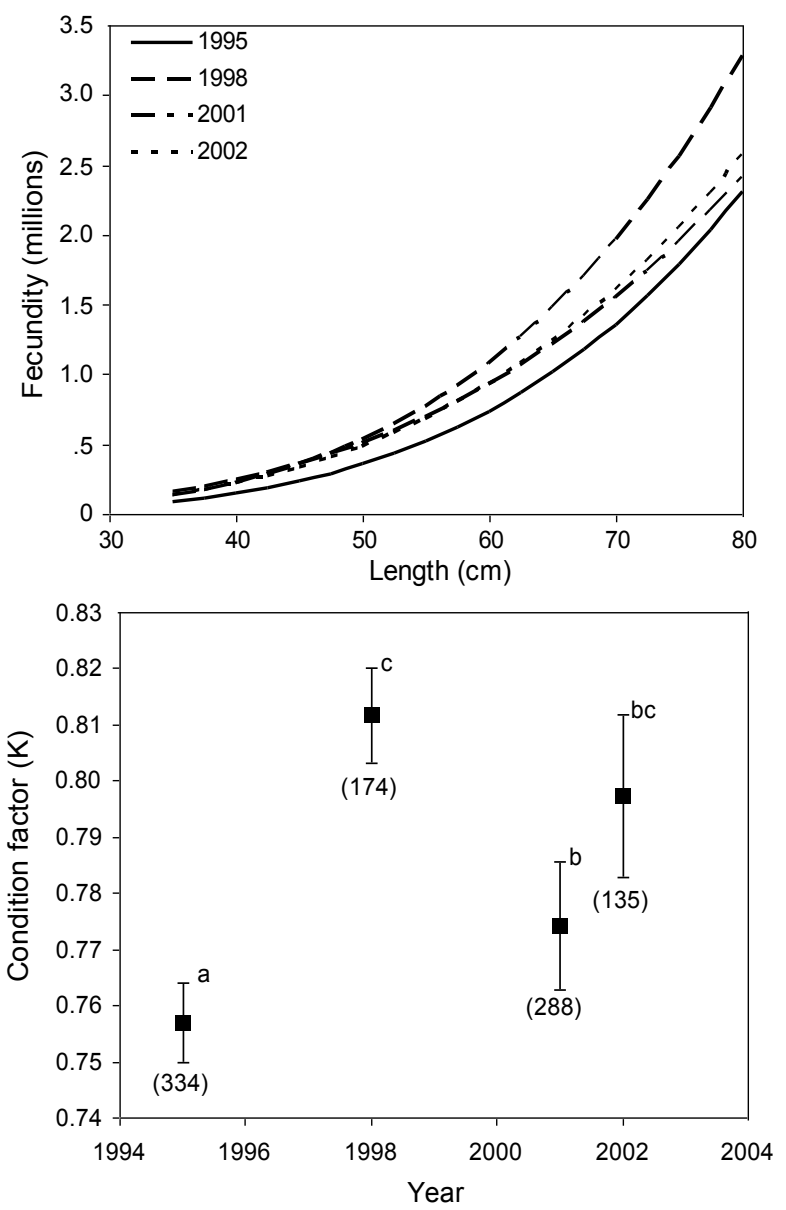

Fig. 4. Fecundity-length relationships (upper panel) and mean condition factor of maturing cod (lower panel) in the northern Gulf of St. Lawrence in 1995, 1998, 2001, and 2002. Significant differences in the condition factor between years are identified by different letters. Number of observations for each year are presented in parenthesis.

consequently, fecundity per season, adult reproductive life span and offspring survival, the elements determining reproductive success.
Variation in reproductive success is a key component for theoretical studies on sexual selection and mating behavior to models of population dynamics (Clutton-Brock, 1988; Myers et al., 1999; Vincent and Giles, 2003). Reproductive success will determine the population's rate of increase which is considered by many as the most important in population dynamics, evolutionary ecology and biology (Roff, 1992; Stearns, 1992; Lande, 1993; Myers et al., 1997; Hutchings, 1999). Intrinsic rate of population growth $(r)$ is commonly use to represent population growth rate. Life tables incorporating age-specific rates of survival and fecundity are used to estimate reproductive rate (i.e., lifetime fecundity) and rate of population growth $(r)$ by solving the Euler-Lotka equation:

$$
\sum_{x=\alpha}^{w} e^{-r x} l_{x} m_{x}=1.0
$$

where $l_{x}$ is the probability of survival to age $x, m_{x}$ is the number of female offspring produced per female at age $x, \alpha$ is the age at first maturity and $w$ is the maximum reproductive age (Caswell, 2001).

Life table analysis was used to estimate intrinsic rate of population growth of cod in the NGSL. Yearspecific demographic parameters (numbers-at-age, lengths-at-age, sex ratio-at-age, proportion of females that are mature-at-age, fecundity-at-age, and survival) were assembled to obtain annual estimates of $r$ for the years 1995, 1998, 2001 and 2002. The number of female offspring produced per female at age $x$ (assuming a 1:1 male:female ratio at birth) was estimated as:

$$
m_{x}=0.5 p_{x} f_{x}
$$

with $p_{x}$ representing the proportion of females that are mature at age $x$ and $f_{x}$ the potential fecundity of a female at age $x$. The proportion of females that were mature-atage was estimated from mean length-at-age and the proportion of females mature-at-length estimated using a logistic equation relating the proportion of mature females to length (Table 4). Fecundity-at-age was estimated from 
TABLE 3. Summary statistics of the multiple regression model relating potential fecundity to fork length and somatic condition factor $(K s)$ for cod in the northern Gulf of St. Lawrence. Fish sampled in the years 1995, 1998, 2001, and 2002 were used for the analysis.

\begin{tabular}{lrrrrc}
\hline \hline & d.f. & Sum of Sq & Mean Sq & $F$ & $\operatorname{Pr}(F)$ \\
\hline $\ln ($ Length $)$ & 1 & 133.5529 & 133.5529 & 1637.585 & $<0.0001$ \\
$\ln (K s)$ & 1 & 8.6658 & 8.6658 & 106.257 & $<0.0001$ \\
Residuals & 459 & 37.4337 & 0.0816 & & \\
\hline
\end{tabular}

TABLE 4. Summary of parameter values used to construct life tables and estimate intrinsic rate of population growth $(r)$ for the different years. Instantaneous rate of total mortality from birth to age $3\left(Z_{0-3}\right)$, instantaneous rate of natural mortality of $3+$ fish $\left(M_{3+}\right)$, length at age, proportion of mature females at length, and potential fecundity at length observed for each year are presented. Parameters of the different equations allowing the calculations of the number of female offspring produced per female at age $x$ are presented. Intrinsic rate of population growth for each year was obtained by solving the Euler-Lotka equation.

\begin{tabular}{|c|c|c|c|c|}
\hline & 1995 & 1998 & 2001 & 2002 \\
\hline Intrinsic rate of population growth $(r)$ & 0.057 & 0.025 & 0.100 & 0.104 \\
\hline Total mortality rate $\left(Z_{0-3}\right)$ & 4.236 & 4.447 & 4.407 & 4.338 \\
\hline Natural mortality rate $\left(M_{3+}\right)$ & 0.4 & 0.3 & 0.2 & 0.2 \\
\hline \multicolumn{5}{|l|}{ Length-at-age $(\text { Length })^{1}$} \\
\hline$a$ & -9.88 & 4.22 & 0.34 & 4.85 \\
\hline$b$ & 33.77 & 25.11 & 27.94 & 25.70 \\
\hline \multicolumn{5}{|l|}{ Proportion mature females at length $(P)^{2}$} \\
\hline$a$ & -11.79 & -14.09 & -6.29 & -7.63 \\
\hline$b$ & 0.32 & 0.34 & 0.14 & 0.16 \\
\hline \multicolumn{5}{|l|}{ Potential fecundity at length $(P F)^{3}$} \\
\hline$a$ & 0.065 & 0.151 & 1.46 & 0.50 \\
\hline$b$ & 3.96 & 3.86 & 3.27 & 3.53 \\
\hline $\begin{array}{l}\text { Length }=b \ln \text { Age }+a \\
P=1 /(1+\exp -(a+b \text { Length })) \\
P F=a \text { Length }\end{array}$ & & & & \\
\hline
\end{tabular}

the relationships between potential fecundity and length and mean length-at-age for each year (Table 4).

The probability of surviving to age $x\left(l_{x}\right)$ was calculated from the results of the sequential population analysis (Fréchet et al., MS 2005). Survival was divided into two categories: survival from birth to age 3 years and survival from age $3+$. Instantaneous rate of mortality per year between the total egg production of the stock (TEP) and the abundance of cod of age 3 was used to calculate survival from birth to age 3 . Values of instantaneous rate of natural mortality $(M=0.2-0.4)$ consistent with cod stock assessment in the NGSL (DFO, MS 2007) were used to determined survival probability of age $3+$ fish. Determination of $r$ was made using PopTools, an add-in tool for PC versions of Microsoft Excel downloadable from: http://www.cse.csiro.au/poptools/.

The use of direct measures of fecundity and other life history parameters defining reproductive potential lead to estimates for $r$ between $0.025-0.104$ for the years 1995, 1998, 2001, and 2002 (Table 4) with lower values in the 1990s when the stock was at its lowest historic estimates of biomass (DFO, MS 2007). Empirical values 
TABLE 5. Intrinsic rate of population growth $(r)$, annual rate of increase in percent per year (\% / year) and doubling time in years (DT) for different cod stocks in the Northwest Atlantic. Values in parentheses from Myers et al. (1997) study represent a correction to original values made by the first author.

\begin{tabular}{lccc}
\hline \hline Stock & $r$ & $\% /$ year & DT \\
\hline Present study & & & \\
$\quad$ N. Gulf of St. Lawrence (3Pn4RS) & $0.025-0.104$ & $2.6-10.9$ & $6.7-27.2$ \\
Myers et al. (1997) & & & \\
$\quad$ Labrador/N.E. Newfoundland (2J3KL) & $0.17(0.26)$ & $18.5(29.7)$ & $4.1(2.7)$ \\
S. Grand Bank (3NO) & 0.27 & 31.0 & 2.6 \\
N. Gulf of St. Lawrence (3Pn4RS) & 0.20 & 22.1 & 3.5 \\
St. Pierre Bank (3Ps) & 0.31 & 36.3 & 2.2 \\
S. Gulf of St. Lawrence (4TVn) & 0.15 & 16.2 & 4.6 \\
Hutchings (1999) & & & \\
Labrador/N.E. Newfoundland (2J3KL) & $0.14-0.16$ & $15.0-17.4$ & $4.3-5.0$ \\
\hline
\end{tabular}

of $r$ for these 4 years are much lower than maximum population growth rates $(r)$ estimated for overfished cod stocks in the Northwest Atlantic (Table 5).

Early estimates of $r$ by Myers et al. (1997) ranged from $0.15-0.31$ (16-36\% increase in population numbers per year), which indicated population doubling times ranging from 2.2-4.6 years (Table 5). However, these overfished stocks did not increase measurably within a few years, which lead to several further lines of inquiry, namely that: 1) the available research surveys were insensitive to detect low rates of increase; 2) the population growth rates were calculated using an age structure that no longer is present and where therefore $r$ was overestimated; or 3) that $r$ has changed due to variation in the life history characteristics influencing $r$ (Hutchings, 1999). Using a stochastic age-structured model, Hutchings (1999) estimated lower $r$ values representing rates of increase between 15-17\% for northern Grand Bank cod (Table 5), and he postulated that these new, much longer estimates of DT (4.3-5.0 years) were more accurate and could explain the slow recovery of these cod stocks. The use of empirical data for NGSL cod gives an even lower potential of increase of the population. The maximum annual rate of increase of the NGSL cod population would vary between $2.6-10.9 \%$ and doubling time of the population would be between 6.7-27.2 years in the absence of fishing. Such low empirical values of $r$ for the NGSL cod stock are not unexpected and could be realistic since this stock which is still subject to a limited fishery has not shown any significant sign of recovery (Shelton et al., 2006).
The ability of a population to recover is determined by the initial population size, the intrinsic rate of population growth $(r)$, and the degree of compensation or depensation (Allee effect) in the spawner-recruit relationship (Jennings, 2001). Calculation of $r$ (and more so of the percentage of increase per year and doubling time) which is central to determine rebuilding times is a metric that is easy to convey to fishery managers and policy makers. In fact, the power behind $r$ is that it integrates a number of life history characteristics that may vary from population to population or even within a population over time. Still, it should be evident from this review that if proxies (e.g., SSB) are used to estimate population growth then the calculations may not properly capture the variation of life history traits that are inherent in natural populations. Development of an analytical approach using $r$, beginning with collection of the required fecundity data, may lead to considerable advancement of our understanding of the productivity and resiliency of exploited fish stocks. Such information has practical application to determine stock rebuilding strategies, to examine the impact of fishing on rebuilding time, and to disentangle the relative role of different demographic parameters (growth, age at maturity, fecundity, juvenile and adult survival, etc.) on $r$ and recovery.

\section{Acknowledgements}

Special thanks to the members of the North Atlantic Fisheries Organisation Working Group on Reproductive Potential (Chair: E.A. Trippel) for stimulating discussions and work to increase knowledge of 
reproductive processes of exploited marine fish stocks. Comments and suggestions of anonymous referees leading to improvement of an earlier manuscript draft are greatly appreciated.

\section{References}

ALMATAR, S. M., and R. S. BAILEY. 1989. Variation in the fecundity and egg weight of herring (Clupea harengus L.). Part 1. Studies in the Firth of Clyde and northern North Sea. J. Cons. Int. Explor. Mer, 45: 113-124.

BAGENAL, T. B. 1978. Method for assessment of fish production in fresh waters. Blackwell Scientific Publications, London, $365 \mathrm{p}$.

BEVERTON, R. J. H., and S. J. HOLT. 1957. On the dynamics of exploited fish populations. Fish. Invest. Minist. Agric. Fish. Food G. B. Ser. II, 19: 1-533.

BLANCHARD, J. L., K. T. FRANK, and J. E. SIMON. 2003. Effects of condition on fecundity and total egg production of eastern Scotian Shelf haddock (Melanogrammus aeglefinus). Can. J. Fish. Aquat. Sci., 60: 321-332. doi:10.1139/f03-024

CASWELL, H. 2001. Matrix population models: construction, analysis, and interpretation, 2nd ed. Sinauer Ass. Inc., USA, $722 \mathrm{p}$.

CHOUINARD, G. A., L. G. CURRIE, G. A. POIRIER, D. P. SWAIN, H. P. BENOIT, T. HURLBUT, D. DAIGLE, and L. SAVOIE. MS 2005. Assessment of the southern Gulf of St. Lawrence cod stock. DFO Can. Sci. Adv. Secr. Res. Doc., 2005/007, 98 p.

CLUTTON-BROCK, T. H. 1988. Reproductive success. Studies of individual variation in contrasting breeding systems. The University of Chicago Press, Chicago, IL, 548 p.

DFO. MS 2007. Assessment of cod stock in the northern gulf of St. Lawrence (3Pn, 4RS) in 2006. DFO Can. Sci. Adv. Secr. Res. Doc., 2007/003, 14 p.

DUTIL, J., and K. BRANDER. 2003. Comparing productivity of North Atlantic cod (Gadus morhua) stocks and limits to growth production. Fish. Oceanogr., 12: 502-512. doi:10.1046/j.1365-2419.2003.00243.x

FRÉCHET, A., J. GAUTHIER, P. SCHWAB, L. PAGEAU, C. SAVENKOFF, M. CASTONGUAY, D. CHABOT, C. TOURNOIS, J.-F. LUSSIER, J. SPINGLE, and F. COLLIER. MS 2005. The status of cod in the northern Gulf of St. Lawrence (3Pn, 4RS) in 2004. DFO Can. Sci. Adv. Secr. Res. Doc., 75 p.

FRIEDLAND, K. D., D. AMA-ABASI, M. MANNING, L. CLARKE, G. KLIGYS, and R. C. CHAMBERS. 2005. Automated egg counting and sizing from scanned images: rapid sample processing and large data volumes for fecundity estimates. J. Sea Res., 54: 307-316. doi:10.1016/j. seares.2005.06.002

FUNAMOTO, T., and I. AOKI. 2002. Reproductive ecology of Japanese anchovy off the Pacific coast of eastern Honshu, Japan. J. Fish. Biol., 60: 154-169. doi:10.1111/j.1095-8649.2002.tb02395.x

HEMPEL, G., and J. H. S. BLAXTER. 1967. Egg weight in Atlantic herring (Clupea harengus L.). J. Cons. Int. Ex- plor. Mer, 31: 170-195.

HISLOP, J. R. G., A. P. ROBB, and J. A. GAULD. 1978. Observations on effects of feeding level on growth and reproduction in haddock, Melanogrammus aeglefinus (L.) in captivity. J. Fish. Biol., 13: 85-98. doi:10.1111/j.1095-8649.1978.tb03416.x

HORWOOD, J. W., M. GREER WALKER, and P. WITTHAMES. 1989. The effect of feeding levels on the fecundity of plaice (Pleuronectes platessa). J. Mar. Biol. Assoc. U.K., 69: 81-92.

HUTCHINGS, J. A. 1999. Influence of growth and survival costs of reproduction on Atlantic cod, Gadus morhua, population growth rate. Can. J. Fish. Aquat. Sci., 56: 1612-1623. doi:10.1139/cjfas-56-9-1612

JENNINGS, S. 2001. Patterns and prediction of population recovery in marine reserves. Rev. Fish Biol. Fish., 10: 209-231. doi:10.1023/A:1016619102955

KAMLER, E. 2005. Parent-egg-progeny relationships in teleost fishes: An energetics perspective. Rev. Fish Biol. Fish., 15: 399-421. doi:10.1007/s11160-006-0002-y

KELLY, K. H., and D. K. STEVENSON. 1985. Fecundity of Atlantic herring (Clupea harengus) from three spawning areas in the western Gulf of Maine, 1969 and 1982. J. Northw. Atl. Fish. Sci., 6: 149-155.

KJESBU, O. S., and J. C. HOLM. 1994. Oocyte recruitment in first-time spawning Atlantic cod (Gadus morhua) in relation to feeding regime. Can. J. Fish. Aquat. Sci., 51: 1893-1898. doi:10.1139/f94-189

KJESBU, O. S., J. KLUNGSOYR, H. KRYVI, P. R. WITTHAMES, and M. GREER WALKER. 1991. Fecundity, atresia, and egg size of captive Atlantic cod (Gadus morhua) in relation to proximate body composition. Can. J. Fish. Aquat. Sci., 48: 2333-2343. doi:10.1139/f91-274

KJESBU, O. S., P. R. WITTHAMES, P. SOLEMDAL, and M. G. WALKER. 1998. Temporal variations in the fecundity of Arcto-Norwegian cod (Gadus morhua) in response to natural changes in food and temperature. J. Sea Res., 40: 303-321. doi:10.1016/S1385-1101(98)00029-X

KLIBANSKY, N., and F. JUANES. 2008. Procedures for efficiently producing high-quality fecundity data on a small budget. Fish. Res., 89: 84-89. doi:10.1016/j.fishres.2007.09.005

KOSLOW, J. A. 1992. Fecundity and the stock-recruitment relationship. Can. J. Fish. Aquat. Sci., 49: 210-217. doi:10.1139/f92-025

KRAUS, G., A. MUELler, K. TRELlA, and F. W. KÖSTER. 2000. Fecundity of Baltic cod: temporal and spatial variation. J. Fish Biol., 56: 1327-1341. doi:10.1111/j.1095-8649.2000.tb02146.x

KRAUS, G., J. TOMKIEWICZ, and F. W. KÖSTER. 2002. Egg production of Baltic cod (Gadus morhua) in relation to variable sex ratio, maturity, and fecundity. Can. J. Fish. Aquat. Sci., 59: 1908-1920. doi:10.1139/f02-159

LAMBERT, Y., and J. D. DUTIL. 2000. Energetic consequences of reproduction in Atlantic cod (Gadus morhua) in relation to spawning level of somatic energy reserves. Can. J. Fish. Aquat. Sci., 57: 815-825. doi:10.1139/cjfas-57-4-815

LAMBERT, Y., J. D. DUTIL, and P. OUELLET. 2000. 
Nutritional condition and reproductive success in wild fish populations. In: Proceedings of the Sixth International Symposium on the Reproductive Physiology of Fish. B. Norberg, O. S. Kjesbu, G. L. Taranger, E. Andersson and S. O. Stefansson (eds.). Bergen, Norway, p. 77-84.

LAMBERT, Y., O. S. KJESBU, G. KRAUS, G. MARTEINSDOTTIR, and A. THORSEN. MS 2005. How variable is the fecundity within and between cod stocks? ICES CM Doc. 2005/Q:13, 20 p.

LAMBERT, Y., N. A. YARAGINA, G. KRAUS, G. MARTEINSDOTTIR, and P. J. WRIGHT. 2003. Using environmental and biological indices as proxies of egg and larval production of marine fish. J. Northw. Atl. Fish. Sci., 33: 115-159. doi:10.2960/J.v33.a7

LANDE, R. 1993. Risks of population extinction from demographic and environmental stochasticity and random catastrophes. Amer. Nat., 142: 911-927. doi:10.1086/285580

MA, Y., O. S. KJESBU, and T. JØRGENSEN. 1998. Effects of ration on the maturation and fecundity in captive Atlantic herring (Clupea harengus). Can. J. Fish. Aquat. Sci., 55: 900-908. doi:10.1139/cjfas-55-4-900

MARSHALL, C. T., O. S. KJESBU, N. A. YARAGINA, P. SOLEMDAL, and O. ULLTANG. 1998. Is spawner biomass a sensitive measure of the reproductive and recruitment potential of northeast Arctic cod? Can. J. Fish. Aquat. Sci., 55: 1766-1783. doi:10.1139/cjfas-55-7-1766

MARSHALL, C. T., C. L. NEEDLE, A. THORSEN, O. S. KJESBU, and N. A. YARAGINA. 2006. Systematic bias in estimates of reproductive potential of an Atlantic cod (Gadus morhua) stock: implications for stock-recruit theory and management. Can. J. Fish. Aquat. Sci., 63: 980-994. doi:10.1139/F05-270

MARSHALL, C. T., L. O'BRIEN, J. TOMKIEWICZ, F. W. KOESTER, G. KRAUS, G. MARTEINSDOTTIR, J. MORGAN, F. SABORIDO-REY, J. L. BLANCHARD, D. H. SECOR, P. J. WRIGHT, N. V. MUKHINA, and H. BJORNSSON. 2003. Developing alternative indices of reproductive potential for use in fisheries management: Case studies for stocks spanning an information gradient. J. Northw. Atl. Fish. Sci., 33: 161-190. doi:10.2960/J.v33. a8

MARSHALL, C. T., N. A. YARAGINA, Y. LAMBERT, and O. S. KJESBU. 1999. Total lipid energy as a proxy for total egg production by fish stocks. Nature, 402: 288-290. doi: $10.1038 / 46272$

MARTEINSDOTTIR, G., and G. BEGG. 2002. Essential relationships incorporating the influence of age, size and condition on variables required for estimation of reproductive potential in Atlantic cod Gadus morhua stocks. Mar. Ecol. Prog. Ser., 235: 235-256. doi:10.3354/meps235235

MCINTYRE, T. M., and J. A. HUTCHINGS. 2003. Smallscale temporal and spatial variation in Atlantic cod ( $\mathrm{Ga}$ dus morhua) life history. Can. J. Fish. Aquat. Sci., 60: 1111-1121. doi:10.1139/f03-090

MESSIEH, S. N. 1976. Fecundity studies on Atlantic herring from the southern Gulf of St. Lawrence and along the Nova Scotia coast. Trans. Amer. Fish. Soc., 105: 384-394. doi:10.1577/15488659(1976)105<384:FSOAHF>2.0.CO;2
MILTON, D. A., S. J. M. BLABER, and N. J. F. RAWLINSON. 1995. Fecundity and egg production of four species of short-lived clupeoid from Solomon Islands, Tropical South Pacific. ICES J. Mar. Sci., 52: 111-125. doi:10.101 6/1054-3139(95)80020-4

MORGAN, M. J., and J. BRATTEY, 2005. Effect of changes in reproductive potential on perceived productivity of three Northwest Atlantic cod (Gadus morhua) stocks. ICES J. Mar. Sci., 62: 65-74. doi:10.1016/j.icesjms.2004.10.003

MURUA, H., G. KRAUS, F. SABORIDO-REY, P. R. WITTHAMES, and S. JUNQUERA. 2003. Procedures to estimate fecundity of marine fish species in relation to their reproductive strategy. J. Northw. Atl. Fish. Sci., 33: 33-54. doi:10.2960/J.v33.a3

MURUA, H., P. LUCIO, M. SANTURTUN, and L. MOTOS. 2006. Seasonal variation in egg production and batch fecundity of European hake Merluccius merluccius (L.) in the Bay of Biscay. J. Fish. Biol., 69: 1304-1316. doi:10.1111/j.1095-8649.2006.01209.x

MURUA, H., and F. SABORIDO-REY. 2003. Female reproductive strategies of marine fish species of the North Atlantic. J. Northw. Atl. Fish. Sci., 33: 23-31. doi:10.2960/J. v33.a2

MYERS, R. A., K. G. BOWEN, and N. J. BARROWMAN. 1999. Maximum reproductive rate of fish at low population sizes. Can. J. Fish. Aquat. Sci., 56: 2404-2419. doi:10.1139/cjfas-56-12-2404

MYERS, R. A., G. MERTZ, and P. S. FOWLOW. 1997. Maximum population growth rates and recovery times for Atlantic cod, Gadus morhua. Fish. Bull., 95: 762-772.

O'BRIEN, L., N. SHEPHERD, and L. COL. MS 2006. Assessment of the Georges Bank Atlantic cod stock for 2005. Northeast Fish. Sci. Cent. Ref. Doc., No. 06-10, 148 p.

OSKARSSON, G. J., and C. T. TAGGART. 2006. Fecundity variation in Icelandic summer-spawning herring and implications for reproductive potential. ICES J. Mar. Sci., 63: 493-503. doi:10.1016/j.icesjms.2005.10.002

RICKER, W. E. 1954. Stock and recruitment. J. Fish. Res. Board Can., 11: 559-623.

RICKMAN, S. J., N. K. DULVY, S. JENNINGS, and J. D. REYNOLDS. 2000. Recruitment variation related to fecundity in marine fishes. Can. J. Fish. Aquat. Sci., 57: 116-124. doi:10.1139/cjfas-57-1-116

ROFF, D. A. 1992. The evolution of life histories: theory and analysis. Chapman and Hall, New York, 535 p.

ROTHSCHILD, B. J., and M. J. FOGARTY. 1989. Spawningstock biomass: A source of error in recruitment/stock relationships and management advice. J. Cons. Int. Explor. Mer, 45: 131-135.

SCOTT, B., G. MARTEINSDOTTIR, and P. WRIGHT. 1999. Potential effects of maternal factors on spawning stockrecruitment relationships under varying fishing pressure. Can. J. Fish. Aquat. Sci., 56: 1882-1890. doi:10.1139/ cjfas-56-10-1882

SHELTON, P. A., A. F. SINCLAIR, G. A. CHOUINARD, R. MOHN, and D. E. DUPLISEA. 2006. Fishing under low productivity conditions is further delaying recovery of Northwest Atlantic cod (Gadus morhua). Can. J. Fish. Aquat. Sci., 63: 235-238. doi:10.1139/f05-253 
SHEPHERD, J. G. 1982. A versatile new stock-recruitment relationship for fisheries, and the construction of sustainable yield curves. J. Cons. Int. Explor. Mer, 40: 67-75.

STEARNS, S. C. 1992. The evolution of life histories. Cambridge University Press, Cambridge, U.K., 249 p.

TANASICHUK, R. W., and D. M. WARE. 1987. Influence of interannual variations in winter sea temperature on fecundity and egg size in Pacific herring (Clupea harengus pallasi). Can. J. Fish. Aquat. Sci., 44: 1485-1495. doi: 10.1139/f87-178

THORSEN, A., and O. S. KJESBU. 2001. A rapid method for estimation of oocyte size and potential fecundity in Atlantic cod using a computer-aided particle analysis system. J. Sea Res., 46: 295-308. doi:10.1016/ S1385-1101(01)00090-9

THORSEN, A., C. T. MARSHALL, and O. S. KJESBU. 2006. Comparison of various potential fecundity models for north-east Arctic cod Gadus morhua, L. using oocyte diameter as a standardizing factor. J. Fish Biol., 69: 1709-1730. doi:10.1111/j.1095-8649.2006.01239.x

TOMKIEWICZ, J., M. J. MORGAN, J. BURNETT, and F. SABORIDO-REY. 2003. Available information for estimating reproductive potential of Northwest Atlantic groundfish stocks. J. Northw. Atl. Fish. Sci., 33: 1-21. doi:10.2960/J.v33.a1

TRIPPEL, E. A. 1998. Egg size and viability and seasonal offspring production of young Atlantic cod. Trans. Am. Fish. Soc., 127: 339-359. doi:10.1577/15488659(1998) 127<0339:ESAVAS >2.0.CO;2

1999. Estimation of stock reproductive potential: history and challenges for Canadian Atlantic gadoid stock assessments. J. Northw. Atl. Fish. Sci., 25: 61-81. doi:10.2960/J.v25.a6
TYLER, A. V., and R. S. DUNN. 1976. Ration, growth, and measures of somatic and organ condition in relation to meal frequency in winter flounder, Pseudopleuronectes americanus, with hypothesis regarding population homeostasis. J. Fish. Res. Board Can., 33: 63-75.

VINCENT, A. C. J., and B. G. GILES. 2003. Correlates of reproductive success in a wild population of Hippocampus whitei. J. Fish Biol., 63: 344-355. doi:10.1046/j.10958649.2003.00154.x

WINTERS, G. H., J. P. WHEELER, and D. STANSBURY. 1993. Variability in the reproductive output of springspawning herring in the north-west Atlantic. ICES J. Mar. Sci., 50: 15-25. doi:10.1006/jmsc. 1993.1003

WOOTTON, R. J. 1992. Constraints in the evolution of fish life histories. Neth. J. Zool., 42: 291-303. doi:10.1163/156854291X00342

1999. Ecology of teleost fishes, 2 nd edition. Kluwer Academic Publishers, The Netherlands, $386 \mathrm{p}$.

YAMADA, T., I. AOKI, and I. MITANI. 1998. Spawning time, spawning frequency and fecundity of Japanese chub mackerel, Scomber japonicus in the waters around the Izu Islands, Japan. Fish. Res., 38: 83-89. doi:10.1016/ S0165-7836(98)00113-1

YARAGINA, N. A., and C. T. MARSHALL. 2000. Trophic influences on interannual and seasonal variation in the liver condition index of Northeast Arctic cod (Gadus morhua). ICES J. Mar. Sci., 57: 42-55. doi:10.1006/ jmsc. 1999.0493

YONEDA, M., and P. J. WRIGHT. 2004. Temporal and spatial variation in reproductive investment of Atlantic cod $\mathrm{Ga}$ dus morhua in the northern North Sea and Scottish west coast. Mar. Ecol. Prog. Ser., 276: 237-248. doi:10.3354/ meps 276237 